\title{
CDISC SDTM Model Version 1.1
}

National Cancer Institute

\section{Source}

National Cancer Institute. CDISC SDTM Model Version 1.1. NCI Thesaurus. Code C161425.

The 1.1 version of the CDISC Study Data Tabulation Model (SDT M). 